\title{
The Impact of Long COVID-19 on Mental Health: Observational 6-Month Follow-Up Study
}

Sarah Houben-Wilke ${ }^{1}$, PhD; Yvonne MJ Goërtz ${ }^{1,2,3}$, MSc; Jeannet M Delbressine ${ }^{1}$, MSc; Anouk W Vaes ${ }^{1}$, PhD; Roy Meys ${ }^{1,2,3}$, MSc; Felipe VC Machado ${ }^{1,2,3}$, MSc; Maarten van Herck ${ }^{1,2,3,4}$, MSc; Chris Burtin ${ }^{4}$, PhD; Rein Posthuma ${ }^{1,2,3}$, MSc, MD; Frits ME Franssen ${ }^{1,2,3}$, MD, Prof Dr; Herman Vijlbrief ${ }^{5}$, MSc; Yvonne Spies $^{5}$, MSc; Alex J van 't Hul ${ }^{6}$, PhD; Martijn A Spruit ${ }^{1,2,3}$, Prof Dr; Daisy JA Janssen ${ }^{1,7}$, MD, Prof Dr

${ }_{1}^{1}$ Department of Research and Education, Ciro, Horn, Netherlands

${ }^{2}$ School of Nutrition and Translational Research in Metabolism, Faculty of Health, Medicine and Life Sciences, Maastricht University, Maastricht, Netherlands

${ }^{3}$ Department of Respiratory Medicine, Maastricht University Medical Center, Maastricht, Netherlands

${ }^{4}$ REVAL Rehabilitation Research Center, BIOMED Research Institute, Faculty of Rehabilitation Sciences, Hasselt University, Diepenbeek, Belgium

${ }^{5}$ Lung Foundation Netherlands, Amersfoort, Netherlands

${ }^{6}$ Department of Pulmonary Disease, Radboud University Medical Center, Nijmegen, Netherlands

${ }^{7}$ Care and Public Health Research Institute, Faculty of Health, Medicine and Life Sciences, Maastricht University, Maastricht, Netherlands

\section{Corresponding Author:}

Sarah Houben-Wilke, PhD

Department of Research and Education

Ciro

Hornerheide 1

Horn, 6085 NM

Netherlands

Phone: 31475587602

Email: sarahwilke@ ciro-horn.nl

\section{Abstract}

Background: The psychological impact of COVID-19 can be substantial. However, knowledge about long-term psychological outcomes in patients with COVID-19 is scarce.

Objective: In this longitudinal, observational study, we aimed to reveal symptoms of posttraumatic stress disorder (PTSD) and symptoms of anxiety and depression up to 6 months after the onset of COVID-19-related symptoms in patients with confirmed COVID-19 and persistent complaints. To demonstrate the impact in nonhospitalized patients, we further aimed to compare these outcomes between nonhospitalized and hospitalized patients.

Methods: Demographics, symptoms of PTSD (Trauma Screening Questionnaire [TSQ] $\geq 6$ points) and symptoms of anxiety and depression (Hospital Anxiety and Depression Scale [HADS] $\geq 8$ points) were assessed at 3 and 6 months after the onset of COVID-19-related symptoms in members of online long COVID-19 peer support groups.

Results: Data from 239 patients with confirmed COVID-19 (198/239, 82.8\% female; median age: 50 [IQR 39-56] years) were analyzed. At the 3-month follow-up, 37.2\% (89/239) of the patients had symptoms of PTSD, 35.6\% (85/239) had symptoms of anxiety, and 46.9\% (112/239) had symptoms of depression, which remained high at the 6-month follow-up (64/239, 26.8\%, $P=.001 ; 83 / 239,34.7 \%, P=.90 ; 97 / 239,40.6 \%, P=.08$, respectively; versus the 3-month follow-up). TSQ scores and HADS anxiety and depression scores were strongly correlated at the 3 - and 6-month follow-ups $(r=0.63-0.71, P<.001)$. Symptoms of PTSD, anxiety, and depression were comparable between hospitalized $(n=62)$ and nonhospitalized $(n=177)$ patients.

Conclusions: A substantial percentage of patients with confirmed COVID-19 and persistent complaints reported symptoms of PTSD, anxiety, or depression 3 and 6 months after the onset of COVID-19-related symptoms. The prevalence rates of symptoms of PTSD, anxiety, and depression were comparable between hospitalized and nonhospitalized patients and merely improved over time. Health care professionals need to be aware of these psychological complications and intervene on time in post-COVID-19 patients with persistent complaints.

Trial Registration: Netherlands Trial Register NTR8705; https://www.trialregister.nl/trial/8705. 
(JMIR Ment Health 2022;9(2):e33704) doi: 10.2196/33704

\section{KEYWORDS}

SARS-CoV-2; corona; COVID-19; post-traumatic stress disorder; anxiety; depression; PASC

\section{Introduction}

A traumatic event is an incident that causes physical, emotional, spiritual, or psychological harm [1]. The impact of a traumatic event varies between individuals. Most individuals are resilient, develop appropriate coping strategies, and recover without long-term consequences. Nevertheless, some experience symptoms such as unwanted upsetting memories, flashbacks, nightmares, emotional distress, or physical reactivity after exposure to traumatic reminders. If symptoms last for more than 1 month, create distress, or interfere with daily functioning, posttraumatic stress disorder (PTSD) needs to be considered [2]. PTSD has major negative consequences for patients and their families $[2,3]$ and is associated with long-term comorbid depression and substance abuse [2], underlining the need to detect and treat the disorder.

Severe illness or acute onset of severe illness can be experienced as a traumatic event [1]. Furthermore, isolation precautions for infection prevention have been shown to be associated with severe mental health problems [4]. Accordingly, COVID-19 might also lead to PTSD. Indeed, previous studies reported prevalences of symptoms of PTSD ranging from $10 \%$ to $30 \%$ in patients discharged from the hospital [5-12]. Prevalences of symptoms of anxiety and depression in these samples vary between $5 \%$ and $42 \%$ [7,9-12] and $14 \%$ and $31 \%$ [6,9,11,12], respectively. A recently published review also confirmed the persistence of symptoms and their physical and psychosocial impact following a COVID-19 infection [13]. However, the authors mainly summarized findings from studies including hospitalized patients and concluded that more research is needed in nonhospitalized patients [13]. Indeed, the impact of so-called "mild" COVID-19 can be substantial [14-16]. To date, knowledge about psychological long-term outcomes in these patients is scarce. Mazza and colleagues [11] studied PTSD, depression, and anxiety in COVID-19 patients who visited the emergency department (ED) and compared outcomes between patients who were hospitalized or managed at home 1 month after discharge or ED visit. Psychological outcomes, including PTSD, major depression, and anxiety, were comparable between both groups or even worse in nonhospitalized patients [11]. So, even "mild" COVID-19 may not only cause symptoms of anxiety and depression but also be a stressor leading to PTSD symptoms.

As symptoms of PTSD often develop after a period of time or get worse over time [17], longer follow-up is needed. Therefore, we aimed to explore the prevalence of PTSD and symptoms of anxiety and depression at 3 and 6 months after the onset of COVID-19 symptoms and to study the association between symptoms of PTSD, anxiety, and depression in patients with confirmed COVID-19. To demonstrate the impact of COVID-19 on mental health, especially in nonhospitalized patients, we aimed to compare these outcomes between nonhospitalized and hospitalized patients. As the number of reports demonstrating a substantial burden of psychological trauma in patients with less severe COVID-19 is increasing [18], we hypothesized in advance that the long-term impact of COVID-19 on mental health, even in nonhospitalized patients, is substantial.

\section{Methods}

\section{Study Design, Setting, and Participants}

Members from 2 Facebook groups for coronavirus patients with persistent complaints in The Netherlands ( 11,000 members; "Corona ervaringen en langdurige klachten!") [19] and Flanders (Belgium, 1200 members; "Corona patiënten met langdurige klachten (Vlaanderen)") [20] as well as 1200 people who registered on the website of the Lung Foundation Netherlands (Coronaplein [21]) were invited to complete an online open survey between June 4, 2020 and June 11, 2020 and between August 31, 2020 and September 8, 2020. In total, 1939 members completed the first survey, of which 1556 consented to be approached for future research (see Multimedia Appendix 1).

\section{Ethical Approval}

The medical ethics committee of Maastricht University stated that the Medical Research Involving Human Subjects Act (WMO) did not apply for this study and that an official approval of this study by the committee was not required (METC2020-1978 and METC2020-2554). The medical ethics committee of Hasselt University formally judged and approved the study (MEC2020/041). All respondents gave digital informed consent at the start of both surveys. Without informed consent, the survey could not be continued. The study was registered in the Dutch trial register. Health status, care dependency, and other characteristics of this study sample have been described elsewhere [14-16,22-25].

\section{Clinical Characteristics}

Demographics (age, gender), marital status (yes, not married, or living with partner), educational level (low, middle, or high), BMI, and self-reported pre-existing comorbidities were assessed. Furthermore, the survey contained questions regarding the diagnosis of COVID-19: self-reported, polymerase chain reaction (PCR)-confirmed, and/or radiologic confirmed. A confirmed diagnosis was based on a computed tomography (CT) scan or reverse transcription PCR (RT-PCR). Self-reported health status (good, moderate, or poor), symptoms during the infection and during follow-up, as well as the date of the onset of these COVID-19 symptoms were assessed as previously described [15,23].

\section{PTSD}

The Trauma Screening Questionnaire (TSQ) was used as a screening instrument for PTSD [26]. The TSQ is a 10-item self-report scale consisting of 5 re-experiencing items and 5 arousal items from the Diagnostic and Statistical Manual of Mental Disorders IV (DSM-IV) criteria for PTSD. 
Re-experiencing items include (1) upsetting thoughts or memories about the event that have come into your mind against your will, (2) upsetting dreams about the event, (3) acting or feeling as though the event was happening again, (4) feeling upset by reminders of the event, and (5) bodily reactions (such as fast heartbeat, stomach churning, sweatiness, dizziness) when reminded of the event.

Arousal items include (1) difficulty falling or staying asleep, (2) irritability or outbursts of anger, (3) difficulty concentrating, (4) heightened awareness of potential dangers to yourself and others, and (5) feeling jumpy or being startled at something unexpected.

For the current study, the event was defined as a "corona infection." Participants were asked whether they experienced each symptom at least twice in the past week. In total, 10 questions could be answered with yes or no. A cut-off score of $\geq 6$ points was used to identify patients at risk of having PTSD [26].

\section{Anxiety and Depression}

Symptoms of anxiety and depression were assessed using the Hospital Anxiety and Depression scale (HADS), which is divided into an anxiety subscale and a depression subscale [27] Total scores for each subscale range from 0 (optimal) to 21 points (worst). A cut-off score of $\geq 8$ points was used to identify the presence of clinically relevant symptoms of anxiety or depression [27,28].

\section{Statistical Analyses}

Continuous data are presented as mean (SD) or median (IQR), as appropriate. Categorical data are presented as absolute and relative frequencies.

Differences between 3- and 6-month follow-ups were evaluated with the McNemar test, paired sample $t$ test, or Wilcoxon signed rank test, as appropriate. Differences between hospitalized (without admission to the intensive care unit) and nonhospitalized patients were tested with chi square tests, independent sample $t$ tests, or Mann-Whitney $U$ tests. Correlations between TSQ and HADS anxiety and depression scores were assessed with scatterplots and Spearman rho.
Correlation coefficients of $0.00-0.19,0.20-0.39,0.40-0.59$, $0.60-0.79$, and 0.80-1.00 were defined as very weak, weak, moderate, strong, or very strong, respectively [29]. Statistics were performed using SPSS version 25.0. A priori, the level of significance was set at $P<.05$.

\section{Results}

\section{Survey Completion}

Of the 1556 patients who completed the first survey about 3 months after the onset of COVID-19-related symptoms and consented to be approached for future research, 1005 patients (65\%) completed the second survey about 6 months after the onset of COVID-19-related symptoms (see Multimedia Appendix 1). For the current study, only patients who completed both surveys and who had a confirmed diagnosis based on CT/RT-PCR were included for analyses $(n=239)$. Results from patients with suspected COVID-19 (ie, patients who did not have a formal COVID-19 test at the time of the suspected infection) who completed both surveys $(n=766)$ are presented online and show similarities to those of patients with a confirmed COVID-19 diagnosis (see Multimedia Appendix 2). Time between symptom onset and completion of the questionnaire was 10.4 (2.4) weeks for the first survey and 22.6 (2.4) weeks for the second survey. As demonstrated in another analysis of the current data [23], the results of the first survey were comparable between patients who did and did not complete the second survey.

\section{Patient Characteristics}

Generally, patients were middle-aged women. The majority of patients were married or living with a partner $(173 / 239,72.4 \%)$ and had no pre-existing comorbidities (142/239, 59.4\%). Self-reported health status was generally good before the infection, which was significantly worse 3 months after infection and during the 6 months of follow-up. During the infection, patients reported a median of 15 (IQR 11-18) different symptoms, which decreased to medians of 6 (IQR 4-9) and 6 (IQR 3-8) symptoms at the 3- and 6-month follow-ups, respectively (Table 1). 
Table 1. Patient characteristics.

\begin{tabular}{|c|c|c|c|c|}
\hline Characteristics & All patients $(n=239)$ & Hospitalized patients $(n=62)$ & Nonhospitalized patients $(\mathrm{n}=177)$ & $P$ value $^{\mathrm{a}}$ \\
\hline Women, n (\%) & $198(82.8)$ & $39(62.9)$ & $159(89.8)$ & $<.001$ \\
\hline Age (years), median (IQR) & $50.0(39.0-56.0)$ & $53.0(47.8-60.0)$ & $48.0(37.5-54.5)$ & $<.001$ \\
\hline BMI $\left(\mathrm{kg} / \mathrm{m}^{2}\right)$, median $(\mathrm{IQR})$ & $26.0(23.4-30.5)$ & $28.2(24.8-32.6)$ & $25.6(23.0-29.4)$ & .005 \\
\hline Married/living with partner, n (\%) & $173(72.4)$ & $43(69.4)$ & $130(73.4)$ & .51 \\
\hline \multicolumn{5}{|l|}{ Educational level, n (\%) } \\
\hline Low & $6(2.5)$ & $6(9.7)$ & $0(0)$ & $<.001$ \\
\hline Medium & $126(52.7)$ & $32(51.6)$ & $94(53.1)$ & .84 \\
\hline High & $107(44.8)$ & $24(38.7)$ & $83(46.9)$ & .27 \\
\hline \multicolumn{5}{|l|}{ Pre-existing comorbidities, n (\%) } \\
\hline 1 & $62(25.9)$ & $23(37.1)$ & $39(22.0)$ & .02 \\
\hline$\geq 2$ & $35(14.6)$ & $11(17.7)$ & $24(13.6)$ & .42 \\
\hline \multicolumn{5}{|c|}{ Good self-reported health status before infection, $\mathbf{n}(\%)$} \\
\hline Before infection & $208(87.0)$ & $49(79.0)$ & $159(89.8)$ & .03 \\
\hline After 3 months & $22(9.2)$ & $10(16.1)$ & $12(6.8)$ & .03 \\
\hline After 6 months & $40(16.7)$ & $12(19.4)$ & $28(15.8)$ & .52 \\
\hline \multicolumn{5}{|c|}{ Number of symptoms, median (IQR) } \\
\hline During infection & $15(11-18)$ & $14(10-17)$ & $15(12-18)$ & .20 \\
\hline After 3 months & $6(4-9)$ & $6(4-8)$ & $6(4-9)$ & .32 \\
\hline
\end{tabular}

${ }^{\mathrm{a}}$ Hospitalized patients compared with nonhospitalized patients.

\section{Symptoms of PTSD}

At 3 months after the onset of symptoms, 37.2\% (89/239) of the patients were at risk for PTSD, which decreased to $26.8 \%$ $(64 / 239)$ at the 6-month follow-up $(P=.001$; Table 2$)$.
At 3 months after the onset of symptoms, patients most frequently experienced problems with "difficulty concentrating" (202/239, 84.5\%), "difficulty falling or staying asleep" (170/239, $71.1 \%$ ), and "upsetting thoughts or memories about the event that have come into your mind against your will" (135/239, $56.5 \%$ ). Of the TSQ items, 4 improved significantly over time (see Figure 1 for details). 
Table 2. Symptoms of posttraumatic stress disorder, anxiety, and depression.

\begin{tabular}{|c|c|c|c|c|c|c|c|}
\hline Assessments & $\begin{array}{l}\text { All patients } \\
(n=239)\end{array}$ & $P$ value $^{\mathrm{a}}$ & $\begin{array}{l}\text { Hospitalized pa- } \\
\text { tients }(n=62)\end{array}$ & $P$ value $^{\mathrm{a}}$ & $\begin{array}{l}\text { Nonhospitalized } \\
\text { patients }(n=177)\end{array}$ & $P$ value $^{\mathrm{a}}$ & $P$ value $^{\mathrm{b}}$ \\
\hline \multicolumn{8}{|l|}{ Trauma Screening Questionnaire } \\
\hline Total score after 3 months, mean (SD) & $4.7(2.5)$ & $<.001$ & $4.7(2.9)$ & .02 & $4.7(2.4)$ & 0.001 & .83 \\
\hline Total score after 6 months, mean (SD) & $4.1(2.5)$ & & $4.2(2.8)$ & & $4.1(2.4)$ & & .89 \\
\hline Total score $\geq 6$ points after 3 months, $\mathrm{n}(\%)$ & $89(37.2)$ & .001 & $27(43.5)$ & .02 & $62(35.0)$ & .02 & .23 \\
\hline Total score $\geq 6$ points after 6 months, $\mathrm{n}(\%)$ & $64(26.8)$ & & $19(30.6)$ & & $45(25.4)$ & & .42 \\
\hline \multicolumn{8}{|l|}{ HADS $^{c}$ anxiety subscale } \\
\hline Total score after 3 months, mean (SD) & $6.5(4.0)$ & .15 & $6.5(4.5)$ & .06 & $6.5(3.8)$ & .51 & .92 \\
\hline Total score after 6 months, mean (SD) & $6.2(4.0)$ & & $5.7(4.3)$ & & $6.3(3.9)$ & & .31 \\
\hline Total score $\geq 8$ after 3 months, $\mathrm{n}(\%)$ & $85(35.6)$ & .90 & $21(33.9)$ & .55 & $64(36.2)$ & .99 & .75 \\
\hline Total score $\geq 8$ after 6 months, $\mathrm{n}(\%)$ & $83(34.7)$ & & $18(29.0)$ & & $65(36.7)$ & & .27 \\
\hline \multicolumn{8}{|l|}{ HADS depression subscale } \\
\hline Total score after 3 months, mean (SD) & $7.2(4.0)$ & .001 & $7.0(4.1)$ & .19 & $7.3(3.9)$ & .003 & .59 \\
\hline Total score after 6 months, mean (SD) & $6.5(3.0)$ & & $6.4(4.6)$ & & $6.6(3.6)$ & & .83 \\
\hline Total score $\geq 8$ after 3 months, $\mathrm{n}(\%)$ & $112(46.9)$ & .08 & $31(50.0)$ & .33 & $81(45.8)$ & .19 & .57 \\
\hline Total score $\geq 8$ after 6 months, $\mathrm{n}(\%)$ & $97(40.6)$ & & $26(41.9)$ & & $71(40.1)$ & & .80 \\
\hline
\end{tabular}

a 3 months compared with 6 months.

${ }^{\mathrm{b}}$ Hospitalized patients compared with nonhospitalized patients.

${ }^{\mathrm{c}}$ HADS: Hospital Anxiety and Depression Scale. 
Figure 1. Percentage of patients reporting each item on the Trauma Screening Questionnaire (TSQ) at 3 and 6 months after the onset of COVID-19 symptoms (n=239). *P $\leq 0.053$ months versus 6 months.

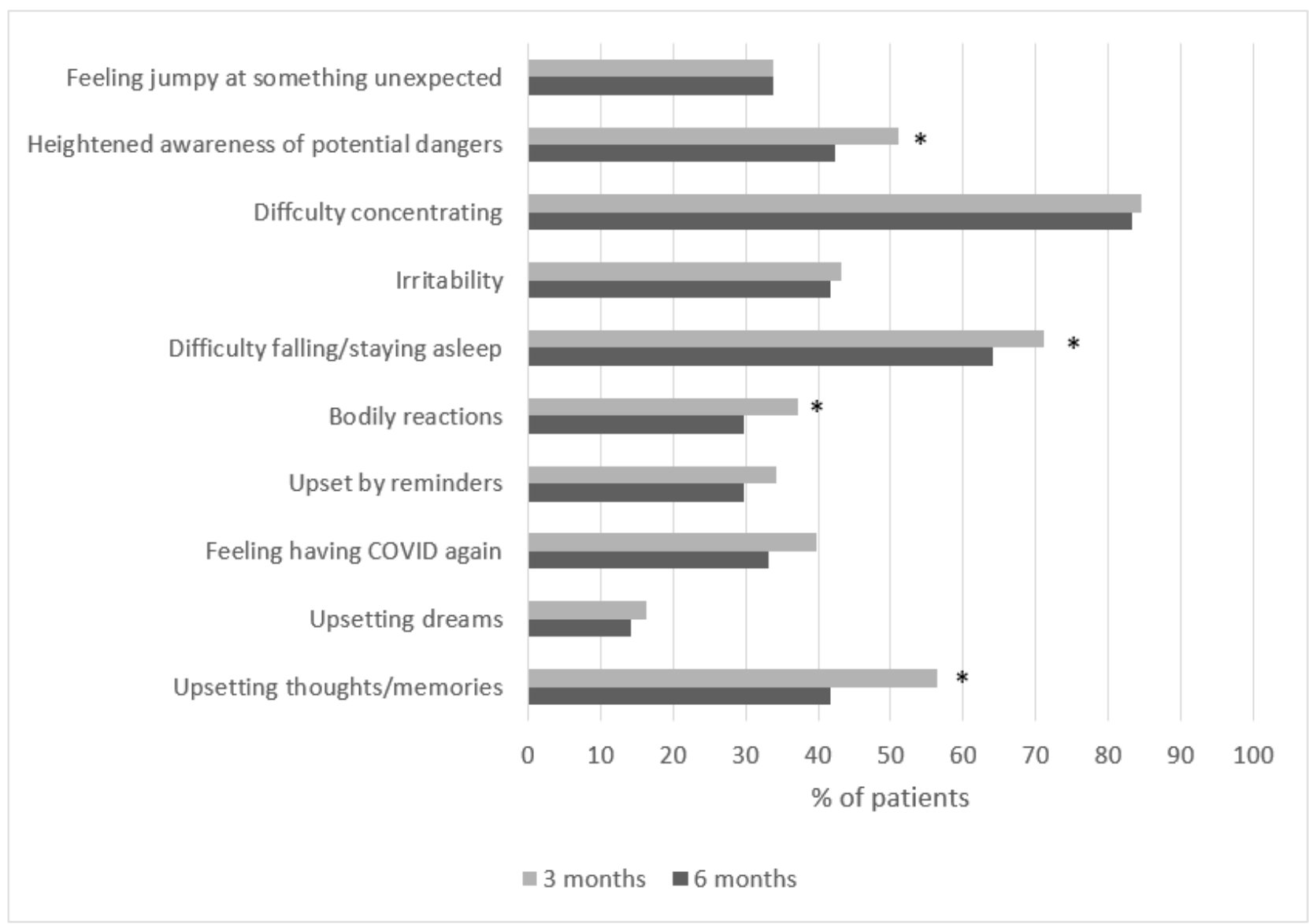

\section{Symptoms of Anxiety and Depression}

Clinically relevant symptoms of anxiety and depression were detected in 35.6\% (85/239) and 46.9\% (112/239), respectively, of all patients at the 3-month follow-up. The prevalence of symptoms of anxiety and depression remained high at the 6-month follow-up (83/239, 34.7\% for symptoms of anxiety, $P=.90 ; 97 / 239,40.6 \%$ for symptoms of depression, $P=.08$; Table 2).

\section{Associations Between Symptoms}

TSQ scores and HADS anxiety and depression scores were strongly correlated at the 3- and 6-month follow-ups $(P=0.631-0.714, P \leq .001$; Figure 2).

Of those patients who were at risk for PTSD at 3- and 6-month follow-ups, two-thirds had clinically relevant symptoms of anxiety and depression. 
Figure 2. Correlations between Trauma Screening Questionnaire (TSQ) scores and Hospital Anxiety and Depression Scale (HADS) scores at (A) 3 and (B) 6 months after the onset of COVID-19-related symptoms.
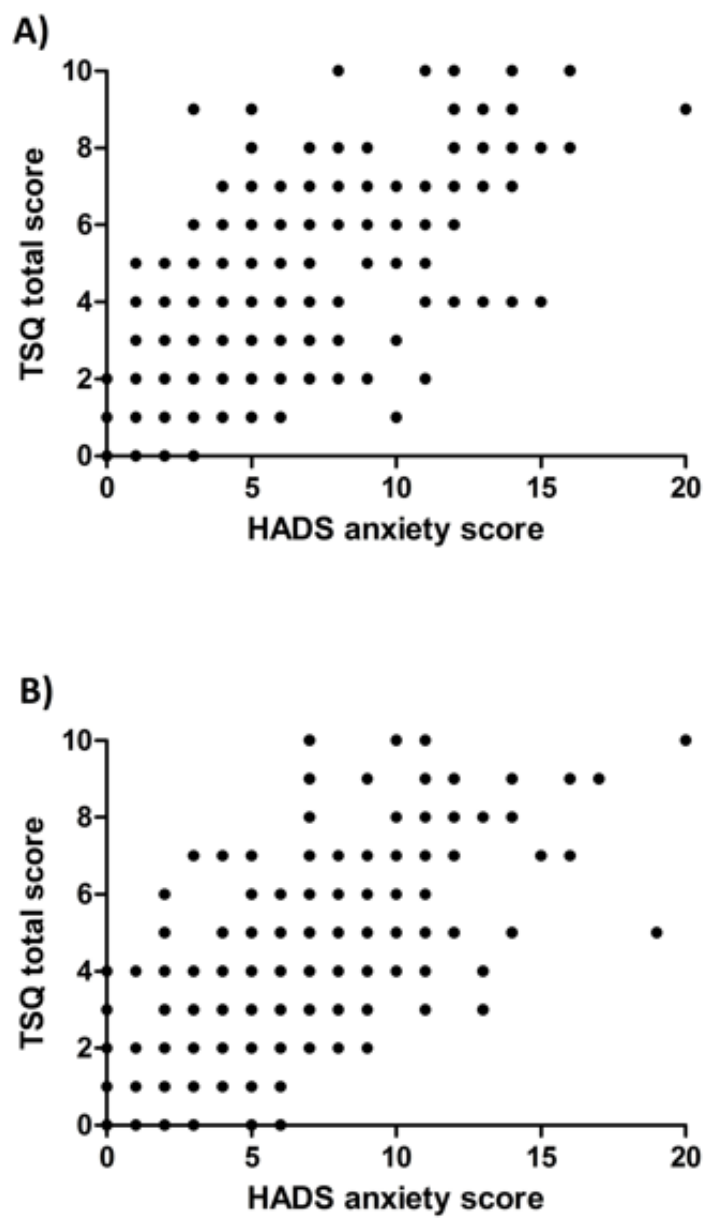

\section{Differences Between Hospitalized and Nonhospitalized Patients}

Compared with hospitalized patients $(n=62)$, nonhospitalized patients $(\mathrm{n}=177)$ more often were women, were younger, had a lower BMI, and reported fewer pre-existing comorbidities. Nonhospitalized patients more often reported good health status before the infection, while more hospitalized patients reported good health status at the 3-month follow-up (Table 1). The prevalences of symptoms of PTSD were comparable between hospitalized and nonhospitalized patients (3-month follow-up: $27 / 62,43.5 \%$ vs $62 / 127,35.0 \%, P=.23$; 6-month follow-up: $19 / 62,30.6 \%$ vs $45 / 127,25.4 \%, P=.42$; Table 2). Prevalence distributions for the separate TSQ items at 3 and 6 months were generally comparable between hospitalized and nonhospitalized patients, except for "upsetting dreams about the event" $(P=.04)$ and "feeling upset by reminders of the event" $(P=.03)$, which were more prominent in hospitalized patients at the 6-month follow-up, and "irritability or outbursts of anger" $(P=.04)$, which was more prominent in nonhospitalized patients at the 6-month follow-up (see Multimedia Appendix 3). Nonhospitalized patients reported a similar level of symptoms of anxiety and depression compared with hospitalized patients at the 3- and 6-month follow-ups (Table 2).
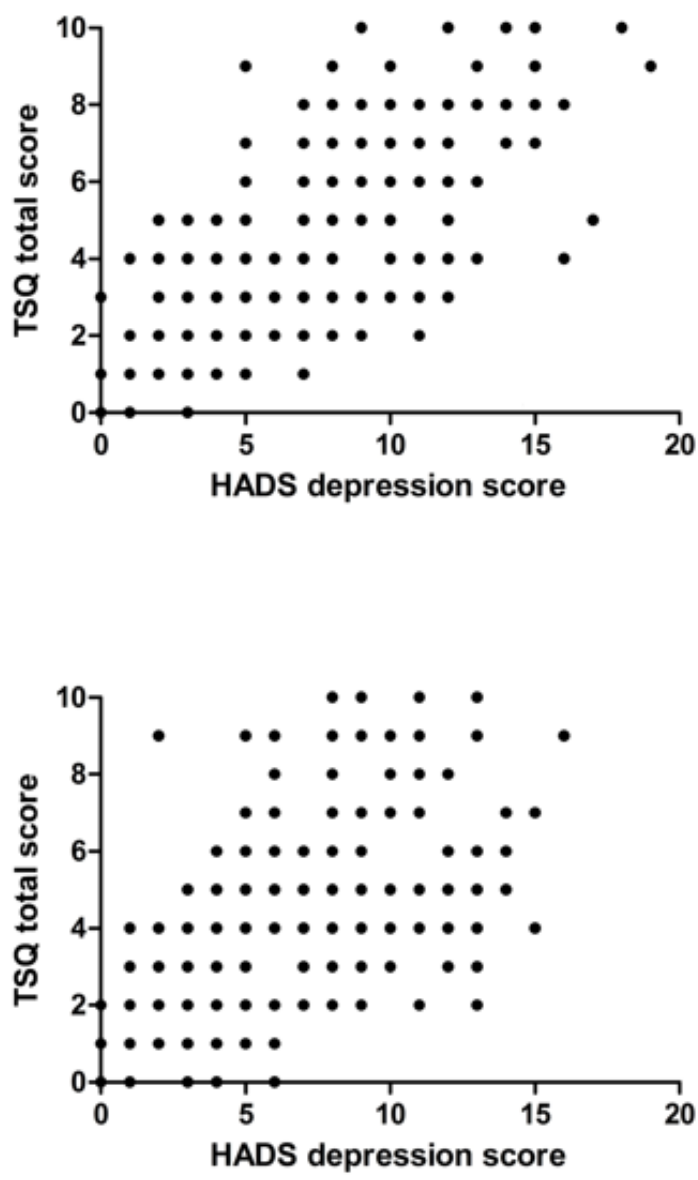

\section{Patients With Suspected COVID-19}

The results of the 766 patients with suspected COVID-19 are comparable to those of patients with a confirmed COVID-19 diagnosis (see Multimedia Appendix 4 and Multimedia Appendix 5).

\section{Discussion}

\section{Principal Findings}

A relevant percentage of nonhospitalized patients were at risk of PTSD and had clinically relevant symptoms of anxiety and depression at 3 and 6 months after the onset of COVID-19-related symptoms. The prevalence rates of symptoms of PTSD, anxiety, and depression were comparable between hospitalized and nonhospitalized patients and merely improved over time. A previous analysis of the current data demonstrated that $95 \%$ of the patients still experience 1 or more symptoms at the 6-month follow-up, which can affect work productivity, functional status, and quality of life [23]. This study indicates the long-term impact of COVID-19 on mental health, especially in nonhospitalized patients with COVID-19 with persistent complaints. 


\section{Comparison With Prior Studies}

This study supports the suggestion by $\mathrm{Gu}$ and colleagues [30] that the impact of COVID-19 is no less than the impact of other stressors (eg, natural disasters, technological accidents). The prevalence of patients at risk of PTSD $(89 / 239,37.2 \%)$ is nearly comparable with the prevalence $(41 \%)$ found in 76 victims of violence and traffic accidents [31]. In addition, a meta-analysis suggested that around $20 \%$ of adult critical care survivors experience PTSD [32], while in previous coronavirus pandemics (SARS and MERS outbreaks), PTSD occurred in 32.2\% of individuals who recovered from coronavirus infection [33]. This demonstrates the long-term impact of severe viral disease. Whether PTSD is also highly prevalent in the aftermath of different COVID-19 populations remains to be determined. Previous published studies reported prevalences of symptoms of PTSD ranging from $10 \%$ to $30 \%$ in patients discharged from the hospital [5-12], which is lower than the current prevalence rates from hospitalized as well as nonhospitalized patients. Hellemons and colleagues [12] reported an even lower prevalence for PTSD (4\%) in patients with COVID-196 months after hospital discharge. With regards to anxiety and depression, a meta-analysis demonstrated pooled prevalences of $47 \%$ and $45 \%$ for anxiety and depression, respectively, in patients with COVID-19 [34]. In addition, Kong and colleagues [35] used the same assessment method (HADS) and the same cut-off score ( $\geq 8$ points) as our study to evaluate symptoms of anxiety and depression in hospitalized patients with COVID-19 and showed prevalences of $35 \%$ and $29 \%$, respectively. This study reported a comparable prevalence of anxiety symptoms, though a higher prevalence of depression symptoms, which might be explained by the fact that our study included patients with long COVID-19 symptoms. This study showed that symptoms of PTSD, anxiety, and depression merely improved over time. This is in line with a recent study demonstrating that anxiety and PTSD did not change between 1- and 3-month follow-ups in COVID-19 survivors after hospital discharge [10]. Our paper supports the authors' conclusion that patient follow-up is an essential component of disease management [10], especially in patients with persistent complaints.

\section{Reasoning Behind Similar Outcomes Between Hospitalized and Nonhospitalized Patients}

Notably, the impact of long COVID-19 on mental health was comparable between hospitalized and nonhospitalized patients, which might, in part, be explained by the following causes.

\section{Lack of Care}

Although the number of symptoms during the acute phase of the infection was comparable, hospitalized patients might have experienced a more severe clinical cause and manifestations of the disease. However, they probably learned to cope with the persistent symptoms of the disease during hospital admission or received aftercare immediately after discharge. Indeed, compared with nonhospitalized patients, hospitalized patients more often received any care from a physiotherapist, medical specialist (eg, pulmonologist), psychologist, dietician, or nurse during or after the onset of symptoms [15]. Moreover, not only during the infection but also in the months following the onset of symptoms, hospitalized patients received physiotherapy or rehabilitation substantially more often than nonhospitalized patients [23]. This might have contributed to the higher percentage of hospitalized patients reporting good self-reported health during the follow-up compared with nonhospitalized patients.

\section{Unmet Needs}

A previous analysis of the current data demonstrated that patients perceive a broad variety of unmet care and information needs, perceive lack of support and understanding from family members, and are worried about incomplete recovery [24]. They indicated the need for certainty and wanted clear information [24], which might further contribute to anxious or depressive feelings or add to "irritability" and "feeling jumpy or being startled at something unexpected." Indeed, in uncertain or frightening situations, clear and precise information is essential [36]. Furthermore, lacking knowledge of the pandemic and less family support were associated with increased risk of depression or anxiety [37].

In addition, patients indicated the need for a test to confirm their diagnosis or certainty that they have had COVID-19: "Without a test, it's all in your mind, it's a psychological thing" [24]. This study demonstrated once again the (mental) impact on patients with suspected COVID-19. We therefore underline the importance of also considering these patients for relevant interventions.

\section{Social Isolation}

The impact of COVID-19 on mental health is tremendous, not only in patients who have been infected with the disease: "Humans are social beings; hence, it is not surprising that extended periods of social isolation are so difficult to cope with" [38]. Being in lockdown can lead to feelings of confinement and loneliness [39]. Loneliness has been described as one of the greatest threats to our health, survival, and well-being [36]. Furthermore, besides the physical harm of COVID-19, periods of confinement can be associated with depression, anxiety, and PTSD [38]. Quarantine has been associated with increased rates of suicide, anger, acute stress disorder, depression, and PTSD, with symptoms continuing even years after quarantine ends [38].

\section{Methodological Considerations}

To the best of our knowledge, this study is one of the first investigating the mental impact of patients with confirmed COVID-19 and persistent complaints at 3- and 6-month follow-ups after the onset of COVID-19-related symptoms. In the following paragraphs, several strengths and limitations are discussed.

First, the majority of the study sample was middle-aged women, which may limit the external validity of the study. However, this needs to be discussed in a broader context: During the COVID-19 pandemic, female gender has been shown to be associated with an increased risk of anxiety or depression as well as PTSD [37], and women and younger age groups were at risk of poorer mental health [40,41]. Additionally, older age was associated with better mental health (ie, lower levels of anxiety and depression). However, the role of age during the 
recovery period is not known yet [42]. Nonetheless, the gender distribution is consistent with previous studies [43-47] and can partly be explained by the higher number of women in COVID-19 support groups [44,45]. Moreover, it has been suggested that long COVID is more common in women than in men [47]. Second, a comprehensive picture of the mental health status of the study sample before infection is not known. We do know that patients with psychiatric history were more likely to have PTSD as demonstrated by Kang and colleagues [48]. However, of those 239 confirmed cases included in our study, $2(0.8 \%)$ patients reported that they had been treated for anxiety, while $5(2.1 \%)$ patients reported that they had been treated for depressive mood before infection (see Multimedia Appendix 6), suggesting a limited influence of pre-existing mental health problems in this study. Third, a longer follow-up period might be relevant to detect even more patients with PTSD symptoms, as there can be a delay of months or even years before symptoms appear for some people [49]. Fourth, there is lack of data about other COVID-19-related stressors (such as death or serious illness [due to COVID-19] of a loved one, social isolation, or loss of work), which might have influenced mental health status. Finally, since the study sample consisted of selected participants recruited through online platforms and specifically targeted patients with persistent complaints, the external validity of our findings is limited.

Taking these considerations into account, this study sample still represents an important, as well as increasing, group of patients with a rising demand for health care services [18].

\section{Recommendations}

Patients with persistent complaints report clinically relevant symptoms of anxiety, depression, and PTSD, supporting the urgent call for rapid response to the mental health impacts of COVID-19 [36], not only for patients but also for the general population [50]. Health care professionals need to be aware that patients, especially women and younger age groups [40,41], are at risk of developing such symptoms and need to intervene on time (eg, prevention of onset of these symptoms during the acute phase or treatment and prevention of progression during follow-up). General practitioners and occupational physicians play a central role in the management of mental disorders during the COVID-19 pandemic, involving early detection, (risk) assessment, and referral [51-53]. Accordingly, psychological-behavioral interventions might be provided if needed, which has been shown to reduce symptoms of anxiety and depression in patients with COVID-19 [35]. Internet-based cognitive and behavioral therapy has been shown to be an effective and acceptable alternative to therapist-delivered treatments for anxiety and depression, while the efficacy for treating PTSD is uncertain [54]. Systemic and well-designed intervention trials with robust outcome evaluations are needed to reveal strategies and models of prevention for PTSD among individuals affected by epidemics of other infectious diseases, such as COVID-19 [50]. Additionally, creating opportunities for patients to access platforms and care team members through telehealth is recommended [55]. Finally, as the experienced distress is a normal human response to a serious crisis, it is therefore advised to recognize and accept these feelings to prevent them from turning into a disorder [36].

\section{Conclusion}

This study shows that a substantial percentage of hospitalized as well as nonhospitalized patients with persistent complaints after COVID-19 has clinically relevant symptoms of PTSD, anxiety, and depression. These symptoms were present at 3 months after the onset of COVID-19-related symptoms and remained high at the 6-month follow-up. Health care professionals as well as patients need to be aware of these symptoms and intervene on time.

\section{Acknowledgments}

The research team acknowledges the valuable input from the patient representatives for developing the survey and the technical support by ASolutions' Martijn Briejers and Oscar Wagemakers. The scientific work of YMJG is financially supported by Lung Foundation Netherlands grant 4.1.16.085, RM is financially supported by Lung Foundation Netherlands grant 5.1.18.232, and FVCM is financially supported by EU-grant ZonMw ERACoSysMed 90030355.

\section{Authors' Contributions}

SHW, JMD, AWV, YMJG, RM, FVCM, and MvH were responsible for the data collection. MAS is the principal investigator of this trial. SH-W, YMJG, and DJAJ drafted the manuscript. All authors interpreted the data as well as critically reviewed, revised, and approved the manuscript.

\section{Conflicts of Interest}

FMEF reports grants and personal fees from AstraZeneca, personal fees from Boehringer Ingelheim, personal fees from Chiesi, personal fees from GlaxoSmithKline, grants and personal fees from Novartis, and personal fees from TEVA, outside the submitted work. DJAJ has received lecture fees from Chiesi and Boehringer Ingelheim within the previous three years, outside the submitted work. MAS reports grants from Lung Foundation Netherlands, grants from Stichting Astma Bestrijding, grants from Boehringer Ingelheim, grants from Chiesi, grants from TEVA, and grants from AstraZeneca, outside the submitted work. SHW, JMD, AWV, YMJG, RM, FVCM, MvH, CB, RP, HV, YS, and AvH have nothing to declare.

\section{Multimedia Appendix 1}

Study flow chart. 
[DOCX File , 24 KB-Multimedia Appendix 1]

\section{Multimedia Appendix 2}

Characteristics of patients with presumed COVID-19.

[DOCX File, 13 KB-Multimedia Appendix 2]

\section{Multimedia Appendix 3}

Percentage of (a) hospitalized and (b) nonhospitalized patients for separate Trauma Screening Questionnaire (TSQ) items 3 and 6 months after the onset of COVID-19 symptoms.

[DOCX File, 30 KB-Multimedia Appendix 3]

\section{Multimedia Appendix 4}

Symptoms of post-traumatic stress disorder, anxiety, and depression.

[DOCX File, 13 KB-Multimedia Appendix 4]

\section{Multimedia Appendix 5}

Percentage of patients for separate Trauma Screening Questionnaire (TSQ) items 3 and 6 months after the onset of COVID-19 symptoms (patients with suspected COVID-19, $\mathrm{n}=766$ ).

[DOCX File, 27 KB-Multimedia Appendix 5]

\section{Multimedia Appendix 6}

Self-reported pre-existing comorbidities.

[DOCX File, 12 KB-Multimedia Appendix 6]

\section{References}

1. Traumatic Events. Healthline. URL: https://www.healthline.com/health/traumatic-events [accessed 2021-06-13]

2. Trauma-Informed Care in Behavioral Health Services. In: Center for Substance Abuse Treatment. Rockville, MD: Substance Abuse and Mental Health Services Administration; 2014.

3. Wintermann G, Petrowski K, Weidner K, Strauß B, Rosendahl J. Impact of post-traumatic stress symptoms on the health-related quality of life in a cohort study with chronically critically ill patients and their partners: age matters. Crit Care 2019 Feb 08;23(1):39 [FREE Full text] [doi: 10.1186/s13054-019-2321-0] [Medline: $\underline{30736830}$ ]

4. Hossain MM, Sultana A, Purohit N. Mental health outcomes of quarantine and isolation for infection prevention: a systematic umbrella review of the global evidence. Epidemiol Health 2020 Jun 02;42:e2020038 [FREE Full text] [doi: 10.4178/epih.e2020038] [Medline: 32512661]

5. Chang MC, Park D. Incidence of post-traumatic stress disorder after coronavirus disease. Healthcare (Basel) 2020 Sep 30;8(4):1 [FREE Full text] [doi: 10.3390/healthcare8040373] [Medline: 33008081]

6. Naidu SB, Shah AJ, Saigal A, Smith C, Brill SE, Goldring J, et al. The high mental health burden of "Long COVID" and its association with on-going physical and respiratory symptoms in all adults discharged from hospital. Eur Respir J 2021 Jun;57(6):1 [FREE Full text] [doi: 10.1183/13993003.04364-2020] [Medline: 33795319]

7. Janiri D, Carfì A, Kotzalidis GD, Bernabei R, Landi F, Sani G, Gemelli Against COVID-19 Post-Acute Care Study Group. Posttraumatic stress disorder in patients after severe COVID-19 infection. JAMA Psychiatry 2021 May 01;78(5):567-569. [doi: 10.1001/jamapsychiatry.2021.0109] [Medline: 33599709]

8. Tarsitani L, Vassalini P, Koukopoulos A, Borrazzo C, Alessi F, Di Nicolantonio C, et al. Post-traumatic stress disorder among COVID-19 survivors at 3-month follow-up after hospital discharge. J Gen Intern Med 2021 Jun;36(6):1702-1707 [FREE Full text] [doi: 10.1007/s11606-021-06731-7] [Medline: 33782888]

9. de Graaf MA, Antoni ML, Ter Kuile MM, Arbous MS, Duinisveld AJF, Feltkamp MCW, et al. Short-term outpatient follow-up of COVID-19 patients: A multidisciplinary approach. EClinicalMedicine 2021 Feb;32:100731 [FREE Full text] [doi: 10.1016/j.eclinm.2021.100731] [Medline: 33532720]

10. DE Lorenzo R, Cinel E, Cilla M, Compagnone N, Ferrante M, Falbo E, et al. Physical and psychological sequelae at three months after acute illness in COVID-19 survivors. Panminerva Med 2021 Jun 01:1 [FREE Full text] [doi: 10.23736/S0031-0808.21.04399-8] [Medline: $\underline{34060280]}$

11. Mazza MG, De Lorenzo R, Conte C, Poletti S, Vai B, Bollettini I, COVID-19 BioB Outpatient Clinic Study group, et al. Anxiety and depression in COVID-19 survivors: Role of inflammatory and clinical predictors. Brain Behav Immun 2020 Oct;89:594-600 [FREE Full text] [doi: 10.1016/j.bbi.2020.07.037] [Medline: 32738287]

12. Hellemons ME, Huijts S, Bek L, Berentschot J, Nakshbandi G, Schurink CAM, et al. Persistent health problems beyond pulmonary recovery up to 6 months after hospitalization for SARS-CoV-2; a longitudinal study of respiratory, physical 
and psychological outcomes. Ann Am Thorac Soc 2021 Sep 28:1. [doi: 10.1513/AnnalsATS.202103-340OC] [Medline: 34582728]

13. Michelen M, Manoharan L, Elkheir N, Cheng V, Dagens D, Hastie C, et al. Characterising long COVID: a living systematic review. BMJ Glob Health 2021 Sep;6(9):2020 [FREE Full text] [doi: 10.1136/bmjgh-2021-005427] [Medline: 34580069]

14. Vaes AW, Machado FVC, Meys R, Delbressine JM, Goertz YMJ, Van Herck M, et al. Care dependency in non-hospitalized patients with COVID-19. J Clin Med 2020 Sep 12;9(9):1 [FRE Full text] [doi: 10.3390/jcm9092946] [Medline: 32932582]

15. Goërtz YMJ, Van Herck M, Delbressine JM, Vaes AW, Meys R, Machado FVC, et al. Persistent symptoms 3 months after a SARS-CoV-2 infection: the post-COVID-19 syndrome? ERJ Open Res 2020 Oct;6(4):1 [FREE Full text] [doi: 10.1183/23120541.00542-2020] [Medline: 33257910]

16. Meys R, Delbressine JM, Goërtz YMJ, Vaes AW, Machado FVC, Van Herck M, et al. Generic and respiratory-specific quality of life in non-hospitalized patients with COVID-19. J Clin Med 2020 Dec 09;9(12):1 [FREE Full text] [doi: 10.3390/jcm9123993] [Medline: 33317214]

17. McFarlane AC. The long-term costs of traumatic stress: intertwined physical and psychological consequences. World Psychiatry 2010 Feb;9(1):3-10 [FREE Full text] [doi: 10.1002/j.2051-5545.2010.tb00254.x] [Medline: 20148146]

18. Badenoch J, Cross B, Hafeez D, Song J, Watson C, Butler M, (The SARS-COV-neuro collaboration). Post-traumatic symptoms after COVID-19 may (or may not) reflect disease severity. Psychol Med 2020 Nov 27:1-2 [FREE Full text] [doi: 10.1017/S003329172000481X] [Medline: 33243309]

19. Corona ervaringen en langdurige klachten!. Facebook. URL: https://www.facebook.com/groups/2367232040359292020 [accessed 2022-02-15]

20. Corona patiënten met langdurige klachten (Vlaanderen). Facebook. URL: https://www.facebook.com/groups/ 241043323639334.2020 [accessed 2022-02-15]

21. Lung Foundation Netherlands. Coronaplein. URL: https://coronaplein.nu/ [accessed 2021-09-09]

22. Machado FVC, Meys R, Delbressine JM, Vaes AW, Goërtz YMJ, van Herck M, et al. Construct validity of the Post-COVID-19 Functional Status Scale in adult subjects with COVID-19. Health Qual Life Outcomes 2021 Feb 03;19(1):40 [FREE Full text] [doi: 10.1186/s12955-021-01691-2] [Medline: 33536042]

23. Vaes AW, Goërtz YMJ, Van Herck M, Machado FVC, Meys R, Delbressine JM, et al. Recovery from COVID-19: a sprint or marathon? 6-month follow-up data from online long COVID-19 support group members. ERJ Open Res 2021 Apr;7(2):1 [FREE Full text] [doi: 10.1183/23120541.00141-2021] [Medline: 34041295]

24. Houben-Wilke S, Delbressine J, Vaes A, Goërtz YMJ, Meys R, Machado F, et al. Understanding and being understood: information and care needs of 2113 patients with confirmed or suspected COVID-19. J Patient Exp 2021;8:2374373521997222-2374373521997229 [FREE Full text] [doi: 10.1177/2374373521997222] [Medline: 34179387]

25. Delbressine JM, Machado FVC, Goërtz YMJ, Van Herck M, Meys R, Houben-Wilke S, et al. The impact of post-COVID-19 syndrome on self-reported physical activity. Int J Environ Res Public Health 2021 Jun 03;18(11):6017 [FREE Full text] [doi: 10.3390/ijerph18116017] [Medline: 34205086]

26. Brewin CR, Rose S, Andrews B, Green J, Tata P, McEvedy C, et al. Brief screening instrument for post-traumatic stress disorder. Br J Psychiatry 2002 Aug;181:158-162. [doi: 10.1017/s0007125000161896] [Medline: 12151288]

27. Zigmond AS, Snaith RP. The hospital anxiety and depression scale. Acta Psychiatr Scand 1983 Jun;67(6):361-370. [doi: 10.1111/j.1600-0447.1983.tb09716.x] [Medline: 6880820]

28. Olssøn I, Mykletun A, Dahl AA. The Hospital Anxiety and Depression Rating Scale: a cross-sectional study of psychometrics and case finding abilities in general practice. BMC Psychiatry 2005 Dec 14;5:46 [FREE Full text] [doi:

10.1186/1471-244X-5-46] [Medline: 16351733]

29. Swinscow TDV. Correlation and regression. In: Statistics at Square One. London, England: BMJ Publishing Group; 1997.

30. Gu Y, Zhu Y, Xu F, Xi J, Xu G. Factors associated with mental health outcomes among patients with COVID-19 treated in the Fangcang shelter hospital in China. Asia Pac Psychiatry 2021 Jun;13(2):e12443. [doi: 10.1111/appy.12443] [Medline: 33135397]

31. Dekkers AMM, Olff M, Näring GWB. Identifying persons at risk for PTSD after trauma with TSQ in the Netherlands. Community Ment Health J 2010 Feb 25;46(1):20-25 [FREE Full text] [doi: 10.1007/s 10597-009-9195-6] [Medline: 19396545]

32. Righy C, Rosa RG, da Silva RTA, Kochhann R, Migliavaca CB, Robinson CC, et al. Prevalence of post-traumatic stress disorder symptoms in adult critical care survivors: a systematic review and meta-analysis. Crit Care 2019 Jun 11;23(1):213 [FREE Full text] [doi: 10.1186/s13054-019-2489-3] [Medline: $\underline{\text { 31186070] }}$

33. Rogers JP, Chesney E, Oliver D, Pollak TA, McGuire P, Fusar-Poli P, et al. Psychiatric and neuropsychiatric presentations associated with severe coronavirus infections: a systematic review and meta-analysis with comparison to the COVID-19 pandemic. The Lancet Psychiatry 2020 Jul;7(7):611-627 [FREE Full text] [doi: 10.1016/S2215-0366(20)30203-0] [Medline: 32437679]

34. Deng J, Zhou F, Hou W, Silver Z, Wong CY, Chang O, et al. The prevalence of depression, anxiety, and sleep disturbances in COVID-19 patients: a meta-analysis. Ann N Y Acad Sci 2021 Feb;1486(1):90-111 [FREE Full text] [doi:

10.1111/nyas.14506] [Medline: 33009668] 
35. Kong X, Kong F, Zheng K, Tang M, Chen Y, Zhou J, et al. Effect of psychological-behavioral intervention on the depression and anxiety of COVID-19 patients. Front Psychiatry 2020;11:586355 [FREE Full text] [doi: 10.3389/fpsyt.2020.586355] [Medline: $\underline{33329130]}$

36. Pietrabissa G, Simpson SG. Psychological consequences of social isolation during COVID-19 outbreak. Front Psychol 2020;11:2201 [FREE Full text] [doi: 10.3389/fpsyg.2020.02201] [Medline: 33013572]

37. Vindegaard N, Benros ME. COVID-19 pandemic and mental health consequences: Systematic review of the current evidence. Brain Behav Immun 2020 Oct;89:531-542 [FREE Full text] [doi: 10.1016/j.bbi.2020.05.048] [Medline: 32485289]

38. Jurblum M, Ng CH, Castle DJ. Psychological consequences of social isolation and quarantine: Issues related to COVID-19 restrictions. Aust J Gen Pract 2020 Dec;49(12):778-783 [FREE Full text] [doi: 10.31128/AJGP-06-20-5481] [Medline: 33254205]

39. Burn W, Mudholkar S. Impact of COVID-19 on mental health: Update from the United Kingdom. Indian J Psychiatry 2020 Sep;62(Suppl 3):S365-S372 [FREE Full text] [doi: 10.4103/psychiatry.IndianJPsychiatry 937 20] [Medline: 33227076]

40. Li LZ, Wang S. Prevalence and predictors of general psychiatric disorders and loneliness during COVID-19 in the United Kingdom. Psychiatry Res 2020 Sep;291:113267 [FREE Full text] [doi: 10.1016/j.psychres.2020.113267] [Medline: $\underline{32623266]}$

41. Smith L, Jacob L, Yakkundi A, McDermott D, Armstrong NC, Barnett Y, et al. Correlates of symptoms of anxiety and depression and mental wellbeing associated with COVID-19: a cross-sectional study of UK-based respondents. Psychiatry Res 2020 Sep;291:113138 [FREE Full text] [doi: 10.1016/j.psychres.2020.113138] [Medline: 32562931]

42. Wilson JM, Lee J, Shook NJ. COVID-19 worries and mental health: the moderating effect of age. Aging Ment Health 2021 Jul;25(7):1289-1296. [doi: 10.1080/13607863.2020.1856778] [Medline: 33291948]

43. Davido B, Seang S, Tubiana R, de Truchis P. Post-COVID-19 chronic symptoms: a postinfectious entity? Clin Microbiol Infect 2020 Nov;26(11):1448-1449 [FREE Full text] [doi: 10.1016/j.cmi.2020.07.028] [Medline: 32712242]

44. Ladds E, Rushforth A, Wieringa S, Taylor S, Rayner C, Husain L, et al. Persistent symptoms after Covid-19: qualitative study of 114 "long Covid" patients and draft quality principles for services. BMC Health Serv Res 2020 Dec 20;20(1):1144 [FREE Full text] [doi: 10.1186/s12913-020-06001-y] [Medline: 33342437]

45. Assaf G, Davis H, McCorkell L, Wei H, O'Neill B, Akrami A. An Analysis of the Prolonged COVID-19 Symptoms Survey by Patient-Led Research Team. Patient Led Research. 2020. URL: https://patientresearchcovid19.com/research/report-1/ [accessed 2022-02-15]

46. Cirulli E, Schiabor BK, Riffle S, Bolze A, Neveux I, Dabe S, et al. Long-term COVID-19 symptoms in a large unselected population. medRxiv. 2020. URL: https://www.medrxiv.org/content/10.1101/2020.10.07.20208702v3 [accessed 2022-02-15]

47. Sudre C, Murray B, Varsavsky T, Graham M, Penfold R, Bowyer R, et al. Attributes and predictors of long COVID. Nat Med 2021 Apr;27(4):626-631 [FREE Full text] [doi: 10.1038/s41591-021-01292-y] [Medline: 33692530]

48. Kang E, Lee SY, Kim MS, Jung H, Kim KH, Kim KN, et al. The psychological burden of COVID-19 stigma: evaluation of the mental health of isolated mild condition COVID-19 patients. J Korean Med Sci 2021 Jan 18;36(3):e33 [FREE Full text] [doi: $10.3346 / \mathrm{jkms} .2021 .36 . \mathrm{e33}]$ [Medline: $\underline{33463098]}$

49. What Is Posttraumatic Stress Disorder? American Psychiatric Association. URL: https://www.psychiatry.org/patients-families/ ptsd/what-is-ptsd [accessed 2021-06-13]

50. Xiao S, Luo D, Xiao Y. Survivors of COVID-19 are at high risk of posttraumatic stress disorder. Glob Health Res Policy 2020;5:29 [FREE Full text] [doi: 10.1186/s41256-020-00155-2] [Medline: 32514428]

51. Cooper J, Phelps AJ, Ng CH, Forbes D. Diagnosis and treatment of post-traumatic stress disorder during the COVID-19 pandemic. Aust J Gen Pract 2020 Dec;49(12):785-789 [FREE Full text] [doi: 10.31128/AJGP-07-20-5557] [Medline: $\underline{33254204]}$

52. Andrade RMD. A company doctor's role during the COVID-19 pandemic. Clinics (Sao Paulo) 2020;75:e1921 [FREE Full text] [doi: 10.6061/clinics/2020/e1921] [Medline: 32401964]

53. Spagnolo L, Vimercati L, Caputi A, Benevento M, De Maria L, Ferorelli D, et al. Role and tasks of the occupational physician during the COVID-19 pandemic. Medicina (Kaunas) 2021 May 12;57(5):1 [FREE Full text] [doi: 10.3390/medicina57050479] [Medline: $\underline{\text { 34065845] }}$

54. Lewis C, Roberts NP, Bethell A, Robertson L, Bisson JI. Internet-based cognitive and behavioural therapies for post-traumatic stress disorder (PTSD) in adults. Cochrane Database Syst Rev 2018 Dec 14;12:CD011710 [FREE Full text] [doi: 10.1002/14651858.CD011710.pub2] [Medline: $\underline{\text { 30550643] }}$

55. Abrams EM, Shaker M, Oppenheimer J, Davis RS, Bukstein DA, Greenhawt M. The challenges and opportunities for shared decision making highlighted by COVID-19. J Allergy Clin Immunol Pract 2020 Sep;8(8):2474-2480.e1 [FREE Full text] [doi: 10.1016/j.jaip.2020.07.003] [Medline: $\underline{\text { 32679348] }}$

\section{Abbreviations}

CT: computed tomography

DSM-IV: Diagnostic and Statistical Manual of Mental Disorders

ED: emergency department 
HADS: Hospital Anxiety and Depression Scale

PTSD: posttraumatic stress disorder

RT-PCR: reverse transcription polymerase chain reaction

TSQ: Trauma Screening Questionnaire

WMO: Medical Research Involving Human Subjects Act

Edited by J Torous; submitted 20.09.21; peer-reviewed by A Joseph, E Kang; comments to author 08.11.21; revised version received 28.11.21; accepted 05.01.22; published 24.02.22

Please cite as:

Houben-Wilke S, Goërtz YMJ, Delbressine JM, Vaes AW, Meys R, Machado FVC, van Herck M, Burtin C, Posthuma R, Franssen FME, Vijlbrief H, Spies $Y$, van 't Hul AJ, Spruit MA, Janssen DJA

The Impact of Long COVID-19 on Mental Health: Observational 6-Month Follow-Up Study

JMIR Ment Health 2022;9(2):e33704

URL: https://mental.jmir.org/2022/2/e33704

doi: $10.2196 / 33704$

PMID:

(OSarah Houben-Wilke, Yvonne MJ Goërtz, Jeannet M Delbressine, Anouk W Vaes, Roy Meys, Felipe VC Machado, Maarten van Herck, Chris Burtin, Rein Posthuma, Frits ME Franssen, Herman Vijlbrief, Yvonne Spies, Alex J van 't Hul, Martijn A Spruit, Daisy JA Janssen. Originally published in JMIR Mental Health (https://mental.jmir.org), 24.02.2022. This is an open-access article distributed under the terms of the Creative Commons Attribution License (https://creativecommons.org/licenses/by/4.0/), which permits unrestricted use, distribution, and reproduction in any medium, provided the original work, first published in JMIR Mental Health, is properly cited. The complete bibliographic information, a link to the original publication on https://mental.jmir.org/, as well as this copyright and license information must be included. 